\title{
SISTEM PENDUKUNG KEPUTUSAN KELAYAKAN PEMBERIAN PINJAMAN KREDIT MENGGUNAKAN METODE TOPSIS PADA CUM CARITAS HKBP PEMATANGSIANTAR
}

\author{
Sahat Sonang S. ${ }^{1)}$, Arifin Tua Purba ${ }^{2)}$, Victor Marudut Mulia Siregar ${ }^{3)}$ \\ ${ }_{1,2,3}$ Teknik Komputer, Politeknik Bisnis Indonesia \\ Email : sahatsonangstg@gmail.com, arifintuaprb20@gmail.com, victor.siregar2@gmail.com
}

\begin{abstract}
This research was conducted to solve the problem of decision making to determine the feasibility of giving loans to CUM Caritas HKBP Pematangsiantar. The applicant's assessment includes an administrative assessment and the survey is still being conducted without using a computerbased decision support system. To simplify the decision making to determine the feasibility of giving the loan, a decision support system was designed using the Topsis method (Technique for Order Preference by Similarity to Ideal Solution). The criteria used consist of: Income, Dependent, Loan Size, Guarantee Value and Number of Installments. The results of the calculation of the case of this study that are eligible for a loan in order are NA2 with a value of 0.6390, NA1 with a value of 0.5737, the third is NA3 with a value of 0.5053, and the last is NA4 with a value of 0.3102. The results of this study can be concluded that the Topsis method can answer or resolve problems faced by CUM Caritas HKBP Pematangsiantar in determining creditworthiness.
\end{abstract}

Keywords: DSS, Topsis, Credit, Loans.

\section{PENDAHULUAN}

Perkembangan teknologi dan ilmu pengetahuan di era digital saat ini sangat signifikan khususnya di bidang teknologi komputer [1]-[3], [4]-[13]. Teknologi komputer telah banyak mempengaruhi kehidupan manusia seperti halnya dalam pengambilan keputusan [14]-[18].

CUM Caritas HKBP Pematangsiantar adalah salah satu Credo Union Modifikasi yang ada dikota Pematangsiantar, CUM Caritas HKBP bediri dengan tujuan untuk membantu masyarakat kota Pematangsiantar kususnya anggota jemaat gereja HKBP agar dapat lebih produktif dan sejahtera. Tujuan tersebut mendorong CUM Caritas HKBP dapat terus berkembang hingga saat ini, dan telah memiliki cabang di Gedung 3 lantai 2 pasar tradisional Horas kota Pematangsiantar. Dengan dibukanya cabang pasar tradisional Horas, diharapkan masyarakat serta anggota dapat lebih mudah dalam melakukan transaksi simpan pinjam di CUM Caritas HKBP Pematangsiantar.

Salah satu cara CUM dalam membantu masyarakat untuk lebih produktif dan sejahtera yaitu dengan, memberikan pinjaman kredit bagi anggota. Pinjaman kredit yang diberikan oleh CUM, pemohon terlebih dahulu diseleksi oleh pihak CUM. Penyeleksian ini dilakukan untuk menentukan layak tidaknya pemohon mendapatkan pinjaman sesuai dengan kriteria dan ketentuan yang berlaku.

Saat ini, penilaian pemohon mencakup penilaian administrasi dan survei masih belum menggunakan sistem pendukung keputusan berbasis komputer. Hasil penilaian administrasi dan survei untuk setiap pemohon dianalisis sedemikian rupa. Selanjutnya diserahkan atau dilaporkan kepada Manager sebagai rekomendasi dalam pengambilan keputusan anggota yang layak memperoleh pinjaman kredit.

Pengambilan keputusan dengan dukungan teknologi komputer menggunakan teknik tertentu menjadikan proses pengambilan keputusan menjadi efisien, efektif, terukur dan objektif. Banyak teknik yang dapat digunakan dalam pengambilan keputusan, salah satu dari teknik tersebut adalah metode Topsis. Metode ini mampu menyelsaikan persoalan penyeleksian alternatif secara terstruktur dengan melibatkan multi kriteria [19]-[23].

Untuk membantu pihak CUM Caritas HKBP Pematangsiantar, maka dibangun sistem pendukung keputusan dengan menerapkan metode Technique for Order Preference by Similarity to Ideal Solution (TOPSIS). TOPSIS adalah salah satu metode pengambilan keputusan multikriteria yang banyak digunakan untuk menyelesaikan pengambilan keputusan dan memiliki 
kemampuan mengukur kinerja relatif dari alternatif-alternatif keputusan. Metode TOPSIS didasarkan pada konsep yang dimana alternatif terbaik tidak saja memiliki jarak terpendek dari solusi ideal positif, tetapi juga memiliki jarak terpanjang dari solusi ideal negatif. Hal ini akan menjadi acuan dalam perangkingan dan memperhitungkan tiap kelebihan dan kekurangan dari alternatif yang akan mengajukan pinjaman kredit, sehingga didapatkan kandidat terbaik yang diinginkan.

\section{METODE PENELITIAN}

\section{Dicision Support Systems (DSS)}

DSS dimaksudkan untuk mendukung para pengambil keputusan manajerial dalam situasi keputusan semi terstruktur. DSS menjadi alat bantu bagi para pengambil keputusan untuk memperluas kapabilitas mereka, namun tidak untuk menggantikan penilaian mereka. DSS ditujukan untuk keputusan-keputusan yang memerlukan penilaian atau pada keputusan-keputusan yang sama sekali tidak dapat didukung oleh algoritma. Definisi awal mengimplikasikan (tidak menyatakan secara spesifik) bahwa sistem akan berbasis komputer, akan beroperasi online interaktif, dan kemungkinan akan memiliki kapabilitas output grafis.

DSS sebagai sistem berbasis komputer yang terdiri dari tiga komponen yang saling berinteraksi : sistem bahasa (mekanisme untuk memberikan komunikasi antara pengguna daan komponen DSS lain), sistem pengetahuan (repositori pengetahuan domain masalah yang ada pada DSS entah sebagai data atau sebagai prosedur, dan sistem pemrosesan masalah (hubungan antara dua komponen lainnya, terdiri dari satu atau lebih kapabilitas manipulasi masalah umum yang diperlukan untuk pengambilan keputusan).

\section{Langkah Pengambilan Keputusan}

Berikut langkah pengambilan keputusan:

a. Mengidentifikasi keputusan

b. Mengumpulkan informasi

c. Mengidentifikasi alternatif

d. Menimbang bukti

e. Memilih alternatif

f. Bertindak selanjutnya

g. Meninjau kembali

\section{HASIL DAN PEMBAHASAN \\ Penentuan Kriteria}

Kriteria yang digunakan terdiri dari: Pendapatan, Tanggungan, Besar Pinjaman, Nilai Jaminan dan Jumlah Angsuran seperti pada tabel 1.

Tabel 1. Daftar Kriteria

\begin{tabular}{|c|l|}
\hline Kode Kriteria & \multicolumn{1}{c|}{ Kriteria } \\
\hline K1 & Pendapatan \\
\hline K2 & Jumlah Tanggungan \\
\hline K3 & Besar Pinjaman \\
\hline K4 & Nilai Jaminan \\
\hline K5 & Jumlah Angsuran \\
\hline
\end{tabular}

Standar nilai algoritma Topsis seperti pada tabel 2 .

Tabel 2. Bobot Keputusan

\begin{tabular}{|l|c|}
\hline \multicolumn{1}{|c|}{ Bobot Keputusan } & Nilai \\
\hline Sangat Penting & 5 \\
\hline Penting & 4 \\
\hline Cukup & 3 \\
\hline Tidak Penting & 2 \\
\hline $\begin{array}{l}\text { Sangat Tidak } \\
\text { Penting }\end{array}$ & 1 \\
\hline
\end{tabular}

Data Pengujian

Data awal sebelum dilakukan proses tahapan algoritma Topsis dapat dilihat pada Tabel 3.

Tabel 3. Alternatif

\begin{tabular}{|c|c|c|c|c|c|c|c|}
\hline Kode & NBA & Nama Anggota & K1 & K2 & K3 & K4 & K5 \\
\hline A0001 & 10891 & NA1 & Rp. 6.500.000 & 3 & Rp. 8.000.000 & Rp. 15.000.000 & 320x \\
\hline A0002 & 11087 & NA2 & Rp. 7.000 .000 & 3 & Rp. 20.000 .000 & Rp. 15.000 .000 & $36 x$ \\
\hline A0003 & 10257 & NA3 & Rp. 2.200 .000 & 2 & Rp. 20.000 .000 & Rp. 55.000.000 & 22x \\
\hline A0004 & 11229 & NA4 & Rp. 5.000.000 & 5 & Rp. 5.000.000 & Rp. 25.000.000 & $10 x$ \\
\hline
\end{tabular}

Dari alternatif diatas, maka dihasilkan tabel rating kecocokan seperti pada tabel 4.

Tabel 4. Rating Kecocokan

\begin{tabular}{|c|c|c|c|c|c|c|c|}
\hline Kode & NBA & Nama Anggota & K1 & K2 & K3 & K4 & K5 \\
\hline A0001 & 10891 & NA1 & 4 & 5 & 3 & 3 & 5 \\
\hline
\end{tabular}




\begin{tabular}{|l|l|l|l|l|l|l|l|}
\hline $\mathrm{A} 0002$ & 11087 & $\mathrm{NA} 2$ & 4 & 4 & 5 & 3 & 4 \\
\hline $\mathrm{A} 0003$ & 10257 & $\mathrm{NA} 3$ & 2 & 3 & 5 & 5 & 3 \\
\hline $\mathrm{A} 0004$ & 11229 & $\mathrm{NA} 4$ & 3 & 5 & 2 & 4 & 2 \\
\hline
\end{tabular}

\section{Hasil Pengujian}

Dari tabel rating kecocokan dilanjutkan analisis dengan menggunakan metode TOPSIS untuk memperoleh matrik keputusan ternormalisasi seperti pada tabel 5 .

\section{Matriks keputusan ternormalisasi}

$$
\begin{aligned}
& r_{i j}=\frac{x_{i j}}{\sqrt{\sum_{i=1}^{m} x_{i j}^{2}}} \\
& x 1=\sqrt{4^{2}+4^{2}+2^{2}+3^{2}}=6.7082 \\
& r_{11}=\frac{x_{11}}{x_{1}}=\frac{4}{6.7082}=0.5963 \\
& r_{21}=\frac{x_{21}}{x_{1}}=\frac{4}{6.7082}=0.5963 \\
& r_{31}=\frac{x_{31}}{x_{1}}=\frac{2}{6.7082}=0.2981 \\
& r_{41}=\frac{x_{41}}{x_{1}}=\frac{3}{6.7082}=0.4472 \\
& x 2=\sqrt{5^{2}}+4^{2}+3^{2}+5^{2}=8.6603 \\
& r_{12}=\frac{x_{12}}{x_{2}}=\frac{5}{8.6603}=0.5773 \\
& r_{22}=\frac{x_{22}}{x_{2}}=\frac{4}{8.6603}=0.4619 \\
& r_{32}=\frac{x_{42}}{x_{2}}=\frac{3}{8.6603}=0.3464 \\
& r_{42}=\frac{x_{42}}{x_{2}}=\frac{5}{8.6603}=0.5773
\end{aligned}
$$

$$
\begin{aligned}
& x 3=\sqrt{3^{2}+5^{2}+5^{2}+2^{2}}=7.9373 \\
& r_{13}=\frac{x_{13}}{x_{3}}=\frac{3}{7.9373}=0.3780 \\
& r_{23}=\frac{x_{23}}{x_{3}}=\frac{5}{7.9373}=0.6299 \\
& r_{33}=\frac{x_{43}}{x_{3}}=\frac{5}{7.9373}=0.6299 \\
& r_{43}=\frac{x_{43}}{x_{3}}=\frac{2}{7.9373}=0.2520 \\
& x 4=\sqrt{3^{2}+3^{2}+5^{2}+4^{2}}=7.6811 \\
& r_{14}=\frac{x_{14}}{x_{4}}=\frac{3}{7.6811}=0.3906 \\
& r_{24}=\frac{x_{24}}{x_{4}}=\frac{3}{7.6811}=0.3906 \\
& r_{34}=\frac{x_{44}}{x_{4}}=\frac{5}{7.6811}=0.6509 \\
& r_{44}=\frac{x_{44}}{x_{4}}=\frac{4}{7.6811}=0.5208 \\
& x 5=\sqrt{5^{2}+4^{2}+3^{2}+2^{2}}=7.3485 \\
& r_{14}=\frac{x_{14}}{x_{4}}=\frac{5}{7.3485}=0.6804 \\
& r_{24}=\frac{x_{24}}{x_{4}}=\frac{4}{7.3485}=0.5443 \\
& r_{34}=\frac{x_{44}}{x_{4}}=\frac{3}{7.3485}=0.4082 \\
& r_{44}=\frac{x_{44}}{x_{4}}=\frac{2}{7.3485}=0.2722
\end{aligned}
$$

Tabel 5. Matriks Ternormalisasi

\begin{tabular}{|c|c|c|c|c|c|}
\hline Kode & K1 & K2 & K3 & K4 & K5 \\
\hline A0001 & 0.5963 & 0.5773 & 0.3780 & 0.3906 & 0.6804 \\
\hline $\mathrm{A} 0002$ & 0.5963 & 0.4619 & 0.6299 & 0.3906 & 0.5443 \\
\hline $\mathrm{A} 0003$ & 0.2981 & 0.3464 & 0.6299 & 0.6509 & 0.4082 \\
\hline $\mathrm{A} 0004$ & 0.4472 & 0.5773 & 0.2520 & 0.5208 & 0.2722 \\
\hline
\end{tabular}

Selanjutnya dilakukan perhitungan matriks keputusan terbobot. Hasil perhitungan dari matriks terbobot dapat dilihat pada tabel 6 .

Tabel 6. Hasil Perhitungan Matriks Terbobot

$\begin{array}{cccccc}\text { Kode } & \mathbf{K 1} & \mathbf{K 2} & \mathbf{K 3} & \mathbf{K 4} & \mathbf{K 5} \\ \mathrm{A} 0001 & 0.5963 * 5 & 0.5773 * 3 & 0.3780 * 3 & 0.3906 * 4 & 0.6804 * 3 \\ \mathrm{~A} 0002 & 0.5963 * 5 & 0.4619 * 3 & 0.6299 * 3 & 0.3906 * 4 & 0.5443 * 3 \\ \mathrm{~A} 0003 & 0.2981 * 5 & 0.3464 * 3 & 0.6299 * 3 & 0.6509 * 4 & 0.4082 * 3 \\ \text { A0004 } & 0.4472 * 5 & 0.5773 * 3 & 0.2520 * 3 & 0.5208 * 4 & 0.2722 * 3\end{array}$


Tabel 7. Matriks Terbobot

\begin{tabular}{|c|c|c|c|c|c|}
\hline Kode & K1 & K2 & K3 & K4 & K5 \\
\hline A0001 & 2.9815 & 1.7319 & 1.134 & 1.5624 & 2.0412 \\
\hline A0002 & 2.9815 & 1.3857 & 1.8897 & 1.5624 & 1.6329 \\
\hline A0003 & 1.4905 & 1.0392 & 1.8897 & 2.6036 & 1.2246 \\
\hline A0004 & 2.2360 & 1.7319 & 0.7560 & 2.0832 & 0.8166 \\
\hline
\end{tabular}

Kemudian, berdasarkan matriks terbobot dihitung solusi ideal positif dan solusi ideal negatif sebagai berikut :

Matriks Solusi Ideal Positif

$$
\begin{gathered}
A^{+}=y_{1}^{+}, y_{2}^{+}, \ldots, y_{n}^{+} \\
y 1^{+}=\operatorname{Max}(2.9815,2.9815,1.4905,2.2360) \\
=2.9815 \\
y 2^{+}=\operatorname{Min}(1.7319,1.3857,1.0392,1.7319) \\
=1.0392 \\
y 3^{+}=\operatorname{Max}(1.1340,1.8897,1.8897,0.7560) \\
=1.8897 \\
y 4^{+}=\operatorname{Max}(1.5624,1.5624,2.6036,2.0832) \\
=2.6036 \\
y 5^{+}=\operatorname{Max}(2.0412,1.6329,1.2246,0.8166) \\
=2.0412
\end{gathered}
$$

\section{Matriks Solusi Ideal Negatif}

$$
\begin{gathered}
A^{-}=y_{1}^{-}, y_{2}^{-}, \ldots, y_{n}^{-} \\
y 1^{-}=\operatorname{Min}(2.9815,2.9815,1.4905,2.2360) \\
=1.4905 \\
y 2^{-}=\operatorname{Max}(1.7319,1.3857,1.0392,1.7319) \\
=1.7319 \\
y 3^{-}=\operatorname{Min}(1.1340,1.8897,1.8897,0.7560) \\
=0.7560 \\
y 4^{-}=\operatorname{Min}(1.5624,1.5624,2.6036,2.0832) \\
=1.5624 \\
y 5^{-}=\operatorname{Min}(2.0412,1.6329,1.2246,0.8166) \\
=0.8166
\end{gathered}
$$

Langkah selanjutnya adalah menghitung jarak dari nilai terbobot setiap alternatif dengan nilai solusi ideal positif maupun solusi ideal negatif sebagai berikut :

a. Menentukan jarak antara nilai terbobot setiap alternatif terhadap solusi ideal positif

$$
\begin{aligned}
D 1^{+} & =\sqrt{(2.9815-2.9815)^{2}+(1.0392-1.7319)^{2}+(1.8897-1.1340)^{2}+(2.6036-1.5624)^{2}+(2.0412-2.0412)^{2}} \\
& =1.4612 \\
D 2^{+} & =\sqrt{(2.9815-2.9815)^{2}+(1.0392-1.3857)^{2}+(1.8897-1.8897)^{2}+(2.6036-1.5624)^{2}+(2.0412-1.6329)^{2}} \\
& =1.1708 \\
D 3^{+} & =\sqrt{(2.9815-1.4905)^{2}+(1.0392-1.0392)^{2}+(1.8897-1.8897)^{2}+(2.6036-2.6036)^{2}+(2.0412-1.2246)^{2}} \\
& =1.7000 \\
D 4^{+} & =\sqrt{(2.9815-2.2360)^{2}+(1.0392-1.7319)^{2}+(1.8897-0.7560)^{2}+(2.6036-2.0832)^{2}+(2.0412-0.8166)^{2}} \\
& =2.0227
\end{aligned}
$$

b. Menentukan jarak antara nilai terbobot setiap alternatif terhadap solusi ideal negatif

$$
\begin{aligned}
D 1^{-} & =\sqrt{(2.9815-1.4905)^{2}+(1.7319-1.7319)^{2}+(1.1340-0.7560)^{2}+(1.5624-1.5624)^{2}+(2.0412-0.8166)^{2}} \\
& =1.9661 \\
D 2^{-} & =\sqrt{(2.9815-1.4905)^{2}+(1.3857-1.7319)^{2}+(1.8897-0.7560)^{2}+(1.5624-1.5624)^{2}+(1.6329-0.8166)^{2}} \\
& =2.0723 \\
D 3^{-} & =\sqrt{(1.4905-1.4905)^{2}+(1.0392-1.7319)^{2}+(1.8897-0.7560)^{2}+(2.6036-1.5624)^{2}+(1.2246-0.8166)^{2}} \\
& =1.7366 \\
D 4^{-} & =\sqrt{(2.2360-1.4905)^{2}+(1.7319-1.7319)^{2}+(0.7560-0.7560)^{2}+(2.0832-1.5624)^{2}+(0.8166-0.8166)^{2}} \\
& =0.9094
\end{aligned}
$$


Langkah penutup adalah menentukan nilai preferensi untuk setiap alternatif.

$$
\begin{aligned}
& V 1=\frac{1.9661}{1.9661+1.4612}=0.5737 \\
& V 2=\frac{2.0723}{2.0723+1.1708}=0.6390 \\
& V 3=\frac{1.7366}{1.7366+1.7000}=0.5053 \\
& V 4=\frac{0.9094}{0.9094+2.0227}=0.3102
\end{aligned}
$$

Pengurutan berdasarkan nilai preferensi yang didapatkan, dari yang terbesar sampai yang terkecil.

Tabel 8. Pengurutan Nilai Preferensi Alternatif

\begin{tabular}{|c|c|c|c|}
\hline Kode & $\begin{array}{c}\text { Kode } \\
\text { Anggota }\end{array}$ & $\begin{array}{c}\text { Nama } \\
\text { Anggota }\end{array}$ & $\begin{array}{c}\text { Nilai } \\
\text { Preferensi }\end{array}$ \\
\hline A0002 & 5121 & NA2 & 0.6390 \\
\hline A0001 & 5022 & NA1 & 0.5737 \\
\hline A0003 & 5001 & NA3 & 0.5053 \\
\hline A0004 & 5011 & NA4 & 0.3102 \\
\hline
\end{tabular}

Dari perhitungan diatas dapat diketahui anggota yang pertama layak untuk diberikan kredit adalah NA2 dengan nilai 0,6390, kedua adalah NA1 dengan nilai 0,5737, ketiga adalah NA3 dengan nilai 0,5053 , dan yang terakhir adalah NA4 dengan nilai 0,3102. Grafik Pengurutan Nilai Preferensi Alternatif dapat dilihat pada gambar 2 .

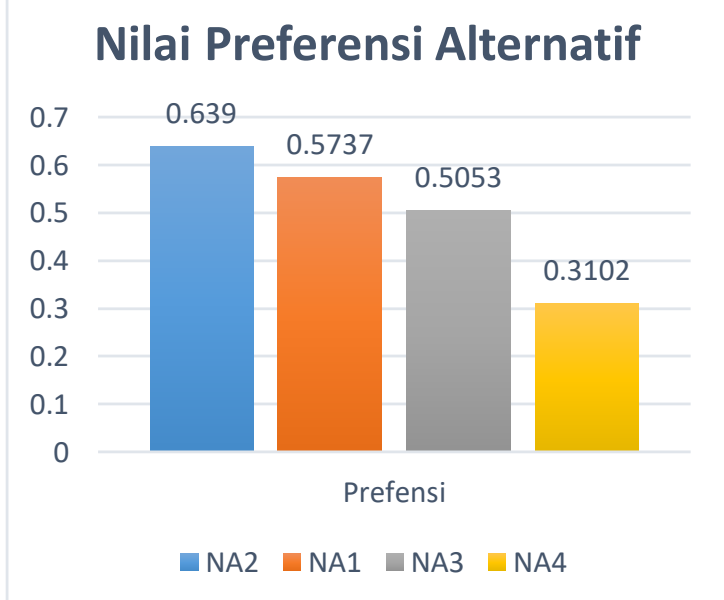

Gambar 2. Grafik Pengurutan Nilai Preferensi Alternatif

\section{KESIMPULAN}

Melalui sistem pendukung keputusan kelayakan pemberian pinjaman kredit yang telah dirancang dengan menggunakan metode
Topsis dapat membantu pihak CUM Caritas HKBP Pematangsiantar dalam memberikan rekomendasi dan solusi yang sesuai dengan kebutuhan pihak CUM Caritas HKBP Pematangsiantar. Sistem pendukung keputusan kelayakan pemberian pinjaman kredit dengan metode Topsis ini dapat mempermudah dan sangat membantu dalam menyelesaikan persoalan yang dihadapi oleh pihak CUM Caritas HKBP Pematangsiantar dalam menentukan kelayakan penerimaan kredit.

\section{REFERENSI}

[1] M. Niswar et al., "Performance evaluation of ZigBee-based wireless sensor network for monitoring patients' pulse status," in Proceedings - 2013 International Conference on Information Technology and Electrical Engineering: "Intelligent and Green Technologies for Sustainable Development", ICITEE 2013, 2013.

[2] P. Adi, D. Prasetya, A. Setiawan, N. Nachrowie, and R. Arifuddin, "Design Of Tsunami Detector Based Sort Message Service Using Arduino and SIM900A to GSM/GPRS Module," Proc. Proc. 2nd Int. Conf. Adv. Sci. Innov. ICASI 2019, 18 July, Banda Aceh, Indones., 2019.

[3] P. D. P. Adi and A. Kitagawa, "Quality of Service and power consumption optimization on the IEEE 802.15.4 pulse sensor node based on Internet of Things," Int. J. Adv. Comput. Sci. Appl., 2019.

[4] A. Ardian, I. Purnama, and V. Sihombing, "Perancangan Aplikasi Pengolah Data Siswa Berbasis Android (Studi Kasus : Mis Nurul Huda Labuhan Batu Selatan)," Pengabdi. Masy. Ika Bina En Pabolo, vol. 1, no. 1, pp. 4053, 2019.

[5] V. Sihombing, "Aplikasi Simade (Sistem Informasi Manajemen Desa) Dalam Meningkatkan Pelayanan Administrasi di Kepenghuluan Bakti Makmur Kecamatan Bagan Sinembah Kab. Rokan Hilir Riau," SISTEMASI, vol. 7, no. September, pp. 292-297, 2018.

[6] V. Sihombing and G. J. Yanris, "PENERAPAN APLIKASI DALAM MENGOLAH ASET DESA (STUDI KASUS: KEPENGHULUAN SRI 
KAYANGAN)," J. Mantik Penusa, vol. 4, no. 1, pp. 12-15, 2020.

[7] Fricles Ariwisanto Sianturi, "Analisa metode teorema bayes dalam mendiagnosa keguguran pada ibu hamil berdasarkan jenis makanan," Tek. Inf. dan Komput., vol. 2, no. 1, pp. 87-92, 2019.

[8] W. Purba, S. Tamba, and J. Saragih, "The effect of mining data k-means clustering toward students profile model drop out potential," J. Phys. Conf. Ser., vol. 1007, no. 1, p. 12049, 2018.

[9] J. Simatupang, "Perancangan Sistem Inventori Barang pada Toko Nichos Jaya Menggunakan Metode FIFO," $J$. Intra Tech, vol. 1, no. 1, pp. 31-42, 2017.

[10] W. Purba, S. Aisyah, and S. P. Tamba, "Perancangan Sistem Pakar Diagnosa Penyakit Mata Katarak Menggunakan Konsep Metode Runut Mundur," JUSIKOM PRIMA (Junal Sist. Inf. Ilmu Komput. Prima), vol. 1, no. 1, 2017.

[11] J. Simatupang and S. Sianturi, "PERANCANGAN SISTEM INFORMASI PEMESANAN TIKET BUS PADA PO. HANDOYO BERBASIS ONLINE," J. Intra Tech, vol. 3, no. 2, pp. 11-25, 2019.

[12] V. Sihombing, "Sistem Informasi Penjualan Mobil Suzuki Di Dealer Bagan Batu," SISTEMASI, vol. 7, no. 2, pp. 113-119, 2018.

[13] G. J. Yanris, "Analisis Dan Implementasi Data Mining Dalam Menganalisa Kendala Akademik Yang Sering Dikeluhkan Mahasiswa AMIK Labuhanbatu (Studi Kasus: Amik Labuhanbatu)," Informatika, vol. 4, no. 1, pp. 15-24, 2016.

[14] Sahat Sonang, "Implementasi K-Means Dalam Evaluasi Kinerja Dosen Politeknik Bisnis Indonesia," $J$. Tekinkom, vol. 1, no. 1, pp. 32-40, 2018.

[15] A. T. Purba, "Sistem Pendukung Keputusan Dalam Penerimaan Mahasiswa Baru Dengan Metode Analytical Hierarchy Process (AHP)," J. Tekinkom, vol. 1, no. 1, pp. 1-7, 2018.

[16] S. P. Tamba, P. Wulandari, M. Hutabarat, M. Christina, and A.
Oktavia, "PENGGUNAAN METODE TOPSIS (TECHNIQUE FOR ORDER PREFERENCE BY SIMILARITY TO IDEAL SOLUTION) UNTUK MENENTUKAN KUALITAS BIJI KOPI TERBAIK BERBASIS ANDROID," J. Mantik Penusa, vol. 3, no. 1, pp. 73-81, 2019.

[17] S. Aisyah and W. Purba, "Aplikasi Sistem Pendukung Keputusan Penilaian Kinerja Karyawan Menggunakan Metode Profile Matching," J. Mahajana Inf., vol. 4, no. 2, pp. 16-20, 2019.

[18] J. Simatupang, "Sistem Pendukung Keputusan Penentuan Karyawan Terbaik Menggunakan Metode Saw Studi Kasus Amik Mahaputra Riau," J. Intra-Tech, vol. 2, no. 1, pp. 73-82, 2018.

[19] R. O. S. Gurning, W. Busse, and M. Lubnan, "Decision Making of Full Speed, Slow Steaming, Extra Slow Steaming and Super Slow Steaming using TOPSIS," Int. J. Mar. Eng. Innov. Res., vol. 2, no. 1, 2017.

[20] A. Azizi, D. O. Aikhuele, and F. S. Souleman, "A Fuzzy TOPSIS Model to Rank Automotive Suppliers," Procedia Manuf., vol. 2, no. February, pp. 159164, 2015.

[21] M. A. G. Fonseca, L. S. De Faria, and S. R. Lourenço, "Original Research Article Original Research Article Open Access Selection of Energy Efficiency Industrial Projects Using Topsis Method," Int. J. Dev. Res., vol. 09, no. 03, pp. 26719-26724, 2019.

[22] V. D. Iswari, F. Y. Arini, and M. A. Muslim, "Decision Support System for the Selection of Outstanding Students Using the AHP-TOPSIS Combination Method," Lontar Komput. J. Ilm. Teknol. Inf., vol. 10, no. 1, p. 40, May 2019.

[23] A. I. Nurani, A. T. Pramudyaningrum, S. R. Fadhila, S. Sangadji, and W. Hartono, "Analytical Hierarchy Process (AHP), Fuzzy AHP, and TOPSIS for Determining Bridge Maintenance Priority Scale in Banjarsari, Surakarta," Int. J. Sci. Appl. Sci. Conf. Ser., vol. 2, no. 1, p. 60, 2017. 